\title{
A Study to Comparison of MIC of Linezolid on MRSA by Micro Broth Dilution and E Strip Method in Teaching Hospital, Karnataka, India
}

\author{
R. Sharlee ${ }^{1}$ and B. Sumangala ${ }^{2 *}$ \\ ${ }^{1}$ Department of Microbiology, Chamarajnagar Institute Medical Sciences, \\ Chamarajanagar, Karnataka, India \\ ${ }^{2}$ Department of Microbiology, Mandya Institute Medical Sciences, \\ Mandya, Karnataka, India \\ *Corresponding author
}

\author{
A B S T R A C T
}

Keywords

MRSA, MIC, Estrips, Micro broth dilution, linezolid

Article Info

Accepted:

22 February 2020

Available Online: 10 March 2020
Although for severe MRSA infections, vancomycin is described as the first-line intravenous drug, vancomycin-resistant and intermediate isolates of Staphylococcus aureus (VRSA \& VISA) have been increasingly reported throughout the world. The therapeutic and life-saving option for VRSA and VISA infections is linezolid. Objective of our study was to assess Minimum inhibitory concentration of linezolid on MRSA by micro broth dilution and E strip method. One hundred fifty isolates from clinical samples were processed. Colonies suggestive of Staphylococcus aureus were identified as MRSA using Cefoxitin $(30 \mu \mathrm{g})$ discasper Clinical and Laboratory Standards Institute (CLSI) guidelines. MRSA Positive isolates were tested for Minimum inhibitory concentration of linezolid by E Strip and Micro broth dilution method. In our study out of 150 isolates of Staphylococcus aureus, 65(43.3\%) were MRSA and 85(56.7\%) were MSSA. A total of 65 MRSA isolates were tested for MIC by Estrip and Micro broth dilution, which showed $100 \%$ sensitivity for linezolid. In the present study, did not come across any resistant strain. In the study total of 65 isolates were tested, According to MIC of linezolid by E Strip which majority (36.9\%) had MIC $<2 \mu \mathrm{g} / \mathrm{ml}$ followed by $30.8 \%$ with $\mathrm{MIC}<1 \mu \mathrm{g} / \mathrm{ml}$, $23 \%$ with $\mathrm{MIC}<4 \mu \mathrm{g} / \mathrm{ml}$ and $9.2 \%$ with $\mathrm{MIC}<0.5 \mu \mathrm{g} / \mathrm{ml}$. In comparison to our study approximately similar MIC values were noted in the study conducted by Stefan Riedel et al., showing $65.1 \%$ with MIC $<1 \mu \mathrm{g} / \mathrm{ml}, 27.9 \%$ with $\mathrm{MIC}<2 \mu \mathrm{g} / \mathrm{ml}, 4.7 \%$ with $\mathrm{MIC}<0.5 \mu \mathrm{g} / \mathrm{ml}$ and $2.3 \%$ with $\mathrm{MIC}<4 \mu \mathrm{g} / \mathrm{ml}$.According to MIC of linezolid by micro broth dilution majority $63.1 \%$ of the isolates were having MIC $<1 \mu \mathrm{g} / \mathrm{ml}$, followed by $26.1 \%$ with $\mathrm{MIC}<2 \mu \mathrm{g} / \mathrm{ml}, 6.1 \%$ with $\mathrm{MIC}<4 \mu \mathrm{g} / \mathrm{ml}$ and $4.7 \%$ with $\mathrm{MIC}<0.5 \mu \mathrm{g} / \mathrm{ml}$.

\section{Introduction}

MRSA strains are critical public health threats because they cause hospital-acquired infections that can be difficult and expensive to treat. Many MRSA strains are susceptible only to vancomycin, and this antibiotic is used extensively to treat patients infected with these organisms. Hence, there is also concern that MRSA may serve as a reservoir of organisms that may give rise to vancomycinresistant strains that could not be killed by available antibiotics. ${ }^{1}$ SOver the past two decades, vancomycin has been considered the 
antibiotic of choice for MRSA infections. ${ }^{2}$ Recent reports describing the therapeutic failure of vancomycin for MRSA infection have aroused considerable concern regarding the emergence of MRSA strains for which there will be no effective therapy. ${ }^{2}$

Several hospital MRSA clones have become multidrug resistant, and have reduced susceptibility to vancomycin. ${ }^{3}$ Although for severe MRSA infections, vancomycin is described as the first-line intravenous drug, vancomycin-resistant and intermediate isolates of Staphylococcus aureus(VRSA \& VISA) have been increasingly reported throughout the world. The therapeutic and life-saving option for VRSA and VISA infections is linezolid. ${ }^{4}$

Linezolid is the first antimicrobial of oxazolidinone group available since 2000. It is the only antibiotic available as an oral formulation for resistant Staphylococcus infection. $^{5}$

It is effective in skin and soft tissue infections, nosocomial pneumonias including VAP, infective endocarditis and MRSA meningitis. It is also effective in eradication of both nasal and throat colonization of MRSA. ${ }^{6}$ Linezolid acts by inhibiting bacterial protein synthesis through binding to the peptidyltransferasecentre (PTC) of the $50 \mathrm{~S}$ ribosomal subunit. ${ }^{5}$

To date, the following mechanisms responsible for linezolid resistance have been reported in clinical isolates of $S$. aureus:

(i) Mutations in the domain $\mathrm{V}$ region of one or more of the five or six copies of the $23 \mathrm{~S}$ rRNA gene ${ }^{7}$ (ii) Acquisition of the plasmidmediated ribosomal methyltransferasecfrgene $^{8}$ and (iii) Deletions or mutations in the ribosomal protein L3 of the PTC. Additional mutations in domain $\mathrm{V}$ of the $23 \mathrm{~S}$
rRNA genes and substitutions in ribosomal protein L4 of the PTC are also reported in laboratory-derived linezolid-resistant $S$. aureusstrains. ${ }^{9}$

The first case of linezolid-resistant staphylococci appeared within 1 year after linezolid was approved for therapeutic use $^{10}$ although linezolid resistance in Staphylococcus aureus is uncommon, emergence has been shown from some parts of the world From India, first case report of linezolid resistance was published in 2011 from Kashmir. ${ }^{11}$

Objective of our study was to assess Minimum inhibitory concentration of linezolidon MRSA by micro broth dilution and E strip method.

\section{Materials and Methods}

\section{Study Setting}

The study was carried in Department of microbiology,MandyaInstitute of medical Sciences, Mandya, Karnataka

\section{Study design}

Cross sectional study

\section{Study period}

January 2017 to December 2017

\section{Sample size}

150 Samples

\section{Source of data}

All isolates of Staphylococcus aureus from various clinical samples like urine, pus, sputum, blood and other body fluid received in microbiology laboratory, Mandya institute of medical science, Mandya. 


\section{Method of collection of data}

The collected samples were inoculated onto MacConkey agar, Blood agar, Mannitol salt agar \&incubated at $37^{\circ} \mathrm{c}$ for $24-48$ hours. Yellow colonies from MSA were sub cultured on Nutrient agar. Staphylococcus aureus were identified and confirmed by Catalase test, Gram's staining and Coagulase test (Slide and tube) with respective controls using golden yellow colonies from Nutrient agar. A total of 150 isolates of Staphylococcus aureus thus obtained were screened for MRSA.

MRSA Positive isolates were tested for Minimum inhibitory concentration of linezolid by E Strip and Micro broth dilution method.

\section{E-Strips}

\section{Requirements}

E-test strips, McFarland standard 0.5, Forceps, Small sterile cotton swabs, wicker hams card (White paper with black lines), peptone broth, $4 \mathrm{ml}$ volumes in tubes, Mueller Hinton II agar plates. ${ }^{12}$

\section{Prepare inoculum}

Remove the E strip from freezer $\left(-20{ }^{\circ} \mathrm{C}\right)$ at least 30 minutes before required. With a loop, touch the top of 3 or 4 colonies \& transfer to a tube of peptone water. Emulsify the inoculum on the inside of the tube to avoid lumps, incubate for $1-2$ hours at $37^{\circ} \mathrm{C}$.Compare turbidity to that in $0.5 \mathrm{McFarland}$ standard by Nephlometry or Wickerhams card. Adjust turbidity of inoculum to match the standard. ${ }^{12}$

\section{Inoculate agar plate}

Lawn the MHA plate within 15 minutes of preparing the adjusted inoculum. Dip a sterile cotton swab into the inoculum and pulling out, slightly rotate the swab several times against the inside of the tube above the fluid level to remove excess liquid. Streak the swab over the entire surface of the agar plate. Rotate the plate approximately $60^{\circ}$, then repeat streaking. Complete the inoculation by running the swab around the rim of the agar. ${ }^{12}$

\section{Apply E strips}

Open E-test package by cutting along the broken line. If strips stick together, they may be pulled apart by handling the section marked E. Do not touch any other area of the strip Apply strips to agar surface using forceps (or E-test applicator if available). Place the strip with the 'E end' at the edge of the plate and with the scale visible. Do not press E-strip. Within 60 seconds E-strip will be absorbed and firmly adhere to the agar surface. $^{12}$

\section{Results interpretation}

On day 2 Read MIC at the point where ellipse intersects the scale. If a MIC value between two-fold dilutions is seen, always round up to the highest value. Remember to read the MIC value at complete inhibition of all growth including isolated colonies.If the intersect differs on either side of the strip, read the MIC as the greater value. Ignore any growth at the edge of the strip.When the growth occurs along the entire strips, report the MIC as $>$ the highest values on the MIC strips. When the inhibition ellipse is below the strip report the MIC <the lowest values on the MIC strips. ${ }^{12}$

\section{To check purity of inoculum}

Transfer inoculum from the tube onto a nutrient agar plate using a $10 \mu \mathrm{l}$ loop. Incubate plates at $35^{\circ} \mathrm{C}$ for 16 to 20 hours in ambient air. Compare the growth with AST plate having E strip. 


\section{Quality control}

S.aureus ATCC 29213

\section{Micro broth dilution}

\section{Requirements}

Micro titre tray, mirror, graduated pipettes, multichannel pipettes, Micro tips, wicker hams card Mueller Hinton broth, Mc Farland standard solution. ${ }^{12}$

\section{Standardisation of inoculum}

From a pure culture plate, pick material from at least 3-4 colonies. Suspend in $4 \mathrm{ml}$ peptone water, Incubate at $37^{\circ} \mathrm{C}$ for $1-2$ hours. Adjust to McFarland 0.5 using (Nephelometer) or Compare visually with the McFarland 0.5 standard using wicker hams card. McFarland 0.5 has approximately $10^{8} \mathrm{CFU} / \mathrm{ml}$, the McFarland matched inoculum has to be diluted further 100 times to get $5 \times 10^{4}$ $\mathrm{CFU} / \mathrm{ml}$.

The suspension should be used for inoculation within 15 minutes to avoid further growth. ${ }^{12}$ Antibiotic solution was diluted with sterile normal saline with different dilutions starting from $0.5,1,2,4,8,16,32 \mu 1$.

\section{Procedure}

The microtitre trays were inoculated with 50 $\mu 1$ of the inoculum suspension using a multichannel pipette each well contains approximately $2.5 \times 10^{4}$ cells. $50 \mu \mathrm{l}$ of antibiotic solution were added to the wellmarked with different dilutions respectively. Plates were sealed and incubated at $37^{\circ} \mathrm{C}$ for 18-22 hrs.

The incubation time is extremely important to obtain reliable end points. Quality control strains are run in parallel to the test strains. ${ }^{12}$
On day 2 Check growth in the positive control wells and no growth in negative control well. MIC is read as the lowest concentration without visible growth. Growth observed from micro titre plate were further cross verified by spot inoculation. Growth from micro titre plate were inoculated onto nutrient agar plate and incubated at $37^{\circ} \mathrm{C}$ for overnight. ${ }^{12}$

On day 3 Results of micro broth dilution by unaided eye were compared with spot inoculation. Note: the MIC is determined from two fold dilutions of the antimicrobial agent. Be aware that "the true" MIC can be anywhere between the observed MIC and the dilution step below. Interpretation of MIC is done according to CLSI guidelines.

\section{Statistical analysis}

Data was entered into Microsoft excel data sheet and was analysed using SPSS 22 version software. Categorical data was represented in the form of Frequencies and proportions.

\section{Results and Discussion}

In the present study, 150 Staphylococcus aureus were screened for MRSA. Out of 150 isolates, 65 (43.3\%) were MRSA and 85 (56.7\%) were MSSA.

Out of 65 MRSA isolates, males have higher prevalence of $67.7 \%$ compared to females showing $32.3 \%$. Out of 85 MSSA isolates, females have higher prevalence of $45.9 \%$ compared to males showing $54.1 \%$.

Majority of MRSA isolated were in the age group $<14$ yrs showing $80 \%$, followed by age group $>60$ yrs showing 52\%,age group between 31-60yrs showing $41.1 \%$ and least $33.3 \%$ between $15-30$ yrs. 
Linezolid is an oxazolidionone derivative, used to treat infections caused by MRSA. MRSA is a pathogen that can result in wide spectrum of infections ranging from simple wound infection to life threatening illnesses because of which antimicrobial susceptibility testing and treating MRSA in very important. First case of linezolid resistance was detected in July 2004.

In our study we collected 150 isolates of Staphylococcus aureus and screened for MRSA, out of which 65 found to be MRSA. In the Present study, Out of 83(55.3\%) males and $67(44.6 \%)$ females screened from 150 isolates, 44(67.7\%) MRSA were isolated from males and 21(32.3\%) were isolated from females.

In comparison with our study, the study conducted by Nadia aslam et al., ${ }^{13}$ shows majority of MRSA were isolated from male patients with $65.2 \%$ and female with $34.8 \%$. Out of 65 MRSA, majority of isolates were isolated from age group less than 14 years with $80 \%$ followed by age group more than 60 years with $52 \%$ in comparison with Shakya et al., ${ }^{13}$ showing $79 \%$ below 14yrs and $48 \%$ above 60 yrs.

Similar findings were observed in a study conducted by Rachel J Gorwiz et al., ${ }^{14}$ showing $72 \%$ below $14 \mathrm{yrs}$ and $47 \%$ above $60 \mathrm{yrs}$. In our study we have isolated MRSA from four different clinical samples at a time. Majority of the studies have taken from wound infections or pus sample received at their laboratory.

Out of 65 MRSA isolates majority were isolated from pus samples 48(73.8\%), followed by sputum $11(16.9 \%)$ and urine 6(9.3\%).Study conducted by Ali Khalid et al., 15 shows similar distribution of MRSA isolates among the clinical samples. 60\% isolated from pus samples, followed by $24 \%$ from sputum and endotracheal secretion, and $10 \%$ from urine samples.

\section{Determination of minimum inhibitory concentration of linezolid by $\mathrm{E}$ Strip}

In the present study total of 65 isolates were tested, out of which majority $(36.9 \%)$ had MIC $<2 \mu \mathrm{g} / \mathrm{ml}$ followed by $30.8 \%$ with $\mathrm{MIC}<1 \mu \mathrm{g} / \mathrm{ml}, 23 \%$ with $\mathrm{MIC}<4 \mu \mathrm{g} / \mathrm{ml}$ and $9.2 \%$ with $\mathrm{MIC}<0.5 \mu \mathrm{g} / \mathrm{ml}$.

In comparison to our study approximately similar MIC values were noted in the study conducted by Stefan Riedel et al., showing $65.1 \%$ with MIC $<1 \mu \mathrm{g} / \mathrm{ml}, 27.9 \%$ with MIC $<2 \mu \mathrm{g} / \mathrm{ml}, 4.7 \%$ with $\mathrm{MIC}<0.5 \mu \mathrm{g} / \mathrm{ml}$ and $2.3 \%$ with $\mathrm{MIC}<4 \mu \mathrm{g} / \mathrm{ml}$. In the study conducted by J.L Kutti et al., ${ }^{16}$ showing $52.5 \%$ with $\mathrm{MIC}<1 \mu \mathrm{g} / \mathrm{ml}$, followed by $42.5 \%$ with $\mathrm{MIC}<0.5 \mu \mathrm{g} / \mathrm{ml}, 2.5 \%$ with $\mathrm{MIC}<2 \mu \mathrm{g} / \mathrm{ml}$ and $\mathrm{MIC}<4 \mu \mathrm{g} / \mathrm{ml}$. Study conducted by Curtis G Gemmel et al., ${ }^{17}$ shows all the isolates tested were having MIC value below $0.5 \mu \mathrm{g} / \mathrm{ml}$.

In the study conducted by Patel et al., ${ }^{18}$ and Yuka kitano et al., ${ }^{19}$ all the isolates had MIC $<2 \mu \mathrm{g} / \mathrm{ml}$. Sader et al., ${ }^{20}$, Ali Khalid et al., ${ }^{15}$ \&YousifTahira et al., ${ }^{21}$ showing similar kind of results with $\mathrm{MIC}<1 \mu \mathrm{g} / \mathrm{ml}$. Study conducted by Vaishali u Thool et al., ${ }^{22}$ shows $8.9 \%$ had $\mathrm{MIC}<4 \mu \mathrm{g} / \mathrm{ml}$ in comparison with our study.

\section{Determination of minimum inhibitory concentration of linezolid by micro broth dilution}

In our study majority $63.1 \%$ of the isolates were having MIC $<1 \mu \mathrm{g} / \mathrm{ml}$, followed by $26.1 \%$ with MIC $<2 \mu \mathrm{g} / \mathrm{ml}, 6.1 \%$ with MIC $<4 \mu \mathrm{g} / \mathrm{ml}$ and $4.7 \%$ with $\mathrm{MIC}<0.5 \mu \mathrm{g} / \mathrm{ml}$. C Muller Seriyas et al., ${ }^{21}$ in his study, he observed that majority $86.7 \%$ of isolates were having $\mathrm{MIC}<0.5 \mu \mathrm{g} / \mathrm{ml}$, followed by $7 \%$ with 
MIC $<2 \mu \mathrm{g} / \mathrm{ml}, 3.3 \%$ with $\mathrm{MIC}<4 \mu \mathrm{g} / \mathrm{ml}$ and $3 \%$ with $\mathrm{MIC}<1 \mu \mathrm{g} / \mathrm{ml}$. In the study conducted by S K Pillai et al., ${ }^{7}, 50 \%$ isolates had MIC value $<4 \mu \mathrm{g} / \mathrm{ml}$, followed by $20 \%$ with $\mathrm{MIC}<8 \mu \mathrm{g} / \mathrm{ml} \quad \& \mathrm{MIC}<16 \mu \mathrm{g} / \mathrm{ml}$ and $10 \%$ with $\mathrm{MIC}<2 \mu \mathrm{g} / \mathrm{ml}$. In the study conducted by Citron et al., and Deborach et al., ${ }^{23}$, all isolates had $\mathrm{MIC}<4 \mu \mathrm{g} / \mathrm{ml}$. In the study conducted by Stefen Riedel et al., ${ }^{24}$ and Robert K Flamm et al., ${ }^{25}$, shows all the isolates had $\mathrm{MIC}<2 \mu \mathrm{g} / \mathrm{ml}$. In the study conducted by GulserenALkatas, D F Basri, Nuramira Mohammed et al., ${ }^{26-28}$ shows all the isolates had $\mathrm{MIC}<1 \mu \mathrm{g} / \mathrm{ml}$.

Table.1 Distribution of MRSA and MSSA among the clinical samples

\begin{tabular}{|c|c|c|c|}
\hline Samples & MRSA (\%) & MSSA (\%) & Total \\
\hline Urine & $6(40.0)$ & $9(60.0)$ & 15 \\
\hline Pus & $48(41.4)$ & $68(58.6)$ & 116 \\
\hline Sputum & $11(61.1)$ & $7(38.9)$ & 18 \\
\hline Throat swab & 0 & $1(100)$ & 01 \\
\hline Total & $\mathbf{6 5}$ & $\mathbf{8 5}$ & $\mathbf{1 5 0}$ \\
\hline
\end{tabular}

Out of 150 isolates, $116(77.3 \%)$ were isolated from pus, $18(12 \%)$ from sputum, $15(10 \%)$ from urine and $1(0.7 \%)$ from throat swab. Out of 65 MRSA, 48 (73.8\%) were isolated from pus, 11(16.9\%) from sputum, 6
(9.3\%) from urine. Out of 85 MSSA, 68(80\%) were isolated from pus, $9(10.6 \%)$ from urine, $7(8.2 \%)$ from sputum and $1(1.2 \%)$ from throat swab.

Table.2 Distribution according to MIC of Linezolide by E-strip and Microbroth dilution

\begin{tabular}{|c|c|c|c|c|}
\hline METHOD & $\begin{array}{c}\text { MIC } \\
<\mathbf{0 . 5} \mathbf{\mu g} / \mathbf{m l}\end{array}$ & $\begin{array}{c}\text { MIC } \\
<\mathbf{1} \boldsymbol{\mu g} / \mathbf{m l}\end{array}$ & $\begin{array}{c}\mathbf{M I C} \\
<\mathbf{2} \boldsymbol{\mu g} / \mathbf{m l}\end{array}$ & $\begin{array}{c}\mathbf{M I C} \\
<\mathbf{4} \mathbf{\mu g} / \mathbf{m l}\end{array}$ \\
\hline Micro broth dilution & $4.7 \%$ & $63.1 \%$ & $26.1 \%$ & $6.1 \%$ \\
\hline E-STRIP & $9.2 \%$ & $30.8 \%$ & $36.9 \%$ & $23 \%$ \\
\hline
\end{tabular}

MRSA Positive isolates were tested for Minimum inhibitory concentration of linezolid by E Strip and micro broth dilution method.

\section{MIC of linezolide by microbroth dilution}

Majority $63.1 \%$ of the isolates were having MIC $<1 \mu \mathrm{g} / \mathrm{ml}$, followed by $26.1 \%$ with MIC $<2 \mu \mathrm{g} / \mathrm{ml}, 6.1 \%$ with $\mathrm{MIC}<4 \mu \mathrm{g} / \mathrm{ml}$ and $4.7 \%$ with $\mathrm{MIC}<0.5 \mu \mathrm{g} / \mathrm{ml}$.

\section{MIC of linezolide by E-strip}

In our study total of 65 isolates were tested, out of which majority(36.9\%) had MIC $<2 \mu \mathrm{g} / \mathrm{ml}$ followed by $30.8 \%$ with MIC $<1 \mu \mathrm{g} / \mathrm{ml}, 23 \%$ with MIC $<4 \mu \mathrm{g} / \mathrm{ml}$ and $9.2 \%$ with MIC $<0.5 \mu \mathrm{g} / \mathrm{ml}$. 
Table.3 Results of MIC of Linezolide by E-strip and Microbroth dilution

\begin{tabular}{|c|c|c|}
\hline \multirow{2}{*}{ Method } & \multicolumn{2}{|c|}{ MIC } \\
\cline { 2 - 3 } & Sensitive (\%) & Resistant (\%) \\
\hline Microbroth Dilution & $65(100)$ & Nil \\
\hline E-STRIP & $65(100)$ & Nil \\
\hline
\end{tabular}

A total of 65 MRSA isolates were tested for MIC by Estrip and microbrothdilution, which showed $100 \%$ sensitivity for linezolid. In our study, we did not come across any resistant strain. In current study, no linezolid resistant strain was isolated. Higher MIC values in the present study shows emerging Linezolid resistance in the hospitals. This emerging linezolid resistance is mainly due to empirical and prolonged therapies, still resistant strains of LRSA is rare.

\section{Acknowledgements}

Authors would like to acknowledge all the subjects participated in the study. Everyone who contributed in the completion of the study including the technical staff

\section{References}

1. Fitzgerald JR, Sturdevant DE, Mackie SM, Gill SR, Musser JM: Evolutionary genomics of Staphylococcus aureus: insights into the origin of methicillinresistant strains and the toxic shock syndrome epidemic. Proc. Natl Acad. Sci. USA2001; 98(15): 8821-8826

2. SieradzkiK,Tomasz A:Alterations Of cell wall structure and metabolism accompany reduced susceptibility to vancomycin in an isogenic series of clinical isolates of Staphylococcus aureus. J Bacteriol2003, 185(24):7103- 7111

3. Holden MT, Feil EJ, Lindsay JA, Peacock SJ, Day NP, Enright MC etal.Complete genomes of two clinical Staphylococcus aureus strains: evidence for the rapid evolution of virulence and drug resistance. Proc Natl AcadSci USA2004 101: 97869791.

4. Peer MA, Nasir RA, Kakru DK, Fomda BA, Bashir G, Sheikh I A. Sepsis due to linezolid resistant Staphylococcus cohniiand Staphylococcus kloosii: First reports of linezolid resistance in coagulase negative Staphylococci from India. Indian J Med Microbiol 2011; 29: 60-62.

5. Tsiodras, S.; Gold, H. S.; Sakoulas, G.; Eliopoulos, G. M.; Wennersten, C.; Venkataraman, L.; Moellering, R. C.; Ferraro, M. J. Linezolid resistance in a clinical isolate of Staphylococcus aureus. Lancet 2001;358: 207-208.

6. Mohammad Fareed Khan, Arvind Neral, Vikas Chandra Yadav3, Farah Aziz Khan1, Sarfaraz Ahmed. Emergence of linezolid resistant Staphylococcus aureus in Bastar tribal region, India. Journal of Microbiology and Infectious. 2012; 2 (3): 127-128.

7. Venkata G. Meka, Satish K. Pillai, George Sakoulas, Christine Wennersten, LataVenkataraman, Paola C. DeGirolami.et.al. Linezolid resistance in sequential Staphylococcusaureusisolates associated with a T2500A mutation in the 23S rRNA gene and loss of a single copy of rRNA. J Infect Dis 2004; 190: 311-317.

8. Morales G, Picazo JJ, Baos E, Candel FJ, Arribi A, Pelaez B et al., Resistance to linezolid is mediated by the cfrgene in the first report of an outbreak of linezolidresistant Staphylococcus aureus. Clin 
Infect Dis 2010; 50:821-825

9. Locke JB, Hilgers M, Shaw KJ. Novel ribosomal mutations in Staphylococcus aureusstrains identified through selection with the oxazolidinones linezolid and torezolid (TR-700). Antimicrob Agents Chemother 2009; 53:5265-5274.

10. Barber M. Methicillin-resistant staphylococci. J ClinPathol 1961;14:38593. [PubMed: 13686776].

11. Ross JE, Farrell DJ, Mendes RE, Sader HS, Jones RN. Eight-year (2002-2009) summary of the linezolid program in European countries. J Chemother 2011; 23:71-76.

12. Clinical and Laboratory Standards Institute. Methods for Dilution Antimicrobial Susceptibility Tests for Bacteria that Grow Aerobically. Approved Standard. 8th ed. Wayne, PA: CLSI Document M7-A8. CLSI; 2018

13. Shakya B, Shrestha S, Mitra T. Nasal carriage rate of Methicillin resistant Staphylococcus aureus among at National Medical College Teaching Hospital, Birgunj, Nepal. Nepal Med Coll J 2010;12:26-9

14. Gorwitz RJ, Jernigan JA. Epidemiology of community-associated Staphylococcus aureus infections. In: Crossley KB, Jefferson KK, Archer GL, Fowler Jr VG (eds.), Staphylococci in human disease. 2nd ed. London: Wiley-Blackwell; 2009: 272-89

15. Ali Khalid, Javaid Usman, UmairaFaiz, Fatima Kaleem, Afreenish Hassan, Maria Omair. In-vitro susceptibility of linezolid against methicillin resistant Staphylococcus aureus at a tertiary care hospital in Pakistan.Journal of Microbiology and Infectious Diseases, 2013; 3 (4): 203-206

16. J. L Kuti, C. R.V. Kiffer, C. M. F. Mendes and D. P. Nicolau1.Pharmacodynamic comparison of linezolid, teicoplanin and vancomycin against clinical isolates of
Staphylococcus aureus and coagulasenegative staphylococci collected from hospitals in Brazil.

17. Gemmell CG, Ford CW. Virulence factor expression by Gram-positive cocci exposed to subinhibitory concentrations of linezolid. J AntimicrobChemother 2010;50:665-72

18. N. Patel,P. Lubanski, S. Ferro, M. Bonafede, S. Harrington, A. Evans, K. Stellrecht, and T. P. Lodise. Correlation between Vancomycin MIC Values and Those of Other Agents against GramPositive Bacteria among Patients with Bloodstream Infections Caused by Methicillin-Resistant Staphylococcus aureus. Antimicrobial agents and chemotherapy, Dec. 2009; p 5141-5144.

19. Yuka Kitano, Shigeki Fujitani, Haruaki Wakatake, MachiYanai, Sari Umekawa, Yosuke Homma, Yasuhiko Tair. The Discrepancy of the Minimum Inhibitory Concentration Results for MethicillinResistant Staphylococcus aureus by Various Measurement Methods: A Comparison of Etest ${ }^{\circledR}$ and Microdilution Methods for Vancomycin, Teicoplanin, Linezolid, Daptomycin and QuinupristinDalfopristin. Emergency Med 5: 286. doi:10.4172/2165-7548.1000286.

20. Sader HS, Romberg PR, Jones RN. 2009. Nine-hospital study comparing broth microdilutionandE-testmethodresults for vancomycinanddaptomycin against methicillin-resistant Staphylococcus aureus. Antimicrob. Agents Chemother. 53:3162-3165.

21. C Muller serieys, H B Drugeon, J Etienne, C Lascols, R Leclercq, J Nguyen et al., Activity of Linezolid against gram positive cocci isolated in French hospitals as determined by three in-vitro susceptibility testing methods. Clinical microbiology and infection. 2004;10(3).

22. Thool UV, Bhoosreddy LG, Wadher JB, et al., Detection of resistance to linezolid 
in Staphylococcus aureus infecting orthopedic patients. IJPM. 2012; 55(3): 361-4.

23. Deborah C. Draghi,Daniel J. Sheehan, Patricia Hogan, and Daniel F. Sahm. In Vitro Activity of Linezolid against Key Gram-Positive Organisms Isolated in the United States: Results of the LEADER 2004 Surveillance Program. American Society for Microbiology Dec. 2005: 49(12): 5024-32.

24. Stefan Riedel,KarMunNeoh,Stephen W. Eisinger, Lisa M. Dam, TsigeredaTekle, Karen. Carroll Comparison of Commercial Antimicrobial Susceptibility Test Methods for Testing of Staphylococcus aureus and Enterococci against Vancomycin, Daptomycin, and Linezolid. Journal of Clinical Microbiology. 2014:52(6): 2216-22

25. Flamm RK, Farrell DJ, Mendes RE, et al., LEADER surveillance program results for 2010: an activity and spectrum analysis of linezolid using 6801 clinical isolates from the United States (61 medical centers). DiagnMicrobiol Infect Dis. 2012;74(1):54-61.

26. GulserenAktas and SengulDerbentli. In vitro activity of daptomycin combined with dalbavancin and linezolid, and dalbavancin with linezolid against MRSA strains. J AntimicrobChemother 2017; 72: 441-443

27. D. F. Basri, N. A. Hamid, S. F. Ishak and A. R. Ghazali. Pterostilbene Reduced Post-Antibiotic Effect Time of Linezolid against Methicillin-Resistant Staphylococcus aureus. Indian J Pharm Sci 2016;78(6):748-754

28. Nur Amira MohdShamsuddin, DayangFredalinaBasri. Anti-methicillin resistant Staphylococcus aureus (MRSA) activity of an acetone extract from the leaves of Canariumodontophyllum(Miq.) The Journal of Phytopharmacology 2018;7(3): 225-229.

\section{How to cite this article:}

Sharlee. R and Sumangala. B. 2020. A Study to Comparison of MIC of Linezolid on MRSA by Micro Broth Dilution and E Strip Method in Teaching Hospital, Karnataka, India. Int.J.Curr.Microbiol.App.Sci. 9(03): 2848-2856. doi: https://doi.org/10.20546/ijcmas.2020.903.328 